\author{
A. C. Roa - M. M. Maya - M. C. Duque
}

J. Tohme - A. C. Allem - M. W. Bonierbale

\title{
AFLP analysis of relationships among cassava and other Manihot species
}

\begin{abstract}
Despite the worldwide importance of cultivated cassava (M. esculenta Crantz) its origin and taxonomic relationships with other species in the genus have not been clearly established. We evaluated a representative sample of the crop's diversity and six wild taxa with AFLPs to estimate genetic relationships within the genus. Groupings of accessions of each species by data analysis corresponded largely with their previous taxonomic classifications. A mixed group, consisting of Manihot esculenta subsp. flabellifolia and M. esculenta subsp. peruviana, was most similar to cassava, while $M$. aesculifolia, M. brachyloba, and $M$. carthaginensis were more distant. Species-specific markers, which may be useful in germ-plasm classification or introgression studies, were suggested by the unique presence of AFLP products in samples of each of the three wild species. Heterogeneity of similarities among individuals of certain species suggested the existence of intraspecific gene pools, a hypothesis that was supported by morphological or ecogeographic evidence with varying degrees of success. Quantitative assessment of genetic diversity revealed greater homogeneity among cassava accessions than among its closest wild relatives. The demonstration of unique genetic diversity in the two M. esculenta subspecies and their genetic similarity to the crop supports the hypothesis that these materials may be the ancestors of cassava.
\end{abstract}

Communicated by G. Wenzel

A. C. Roa - M. M. Maya - M. C. Duque - J. Tohme M. W. Bonierbale ${ }^{1}(\Delta)$

Centro Internacional de Agricultura Tropical - CIAT, Apartado Aéreo 6713, Cali, Colombia

\footnotetext{
A. C. Allem

Centro Nacional de Pesquisa de Recursos Genéticos e Biotecnologia (CENARGEN), Empresa Brasileira

de Pesquisa Agropecuária (EMBRAPA), Brasília, D.F., Brazil

Present address:

${ }^{1}$ Centro International de la Papa (CIP), Apartado 1558,

Lima IZ, Peru
}

Key words Cassava - Manihot genus - AFLP . Genetic diversity - Wild relatives of cassava

\section{Introduction}

The genus Manihot (Euphorbiaceae) is native to the Neotropics, growing in diverse habitats between southern USA and Argentina (Rogers and Appan 1973). Manihot species are perennials and vary from acaulescent shrubs to trees of $10-12 \mathrm{~m}$. Most produce tuberous roots, and some, such as cassava (Manihot esculenta Crantz), accumulate large quantities of starch. Cassava is a major tropical crop, produced mainly by small farmers for food and small-scale industrial use. It occupies fourth place, after rice, sugarcane and maize, as a source of calories in the human diet, feeding more than 500 million people in Africa, Asia, and Latin America (Cock 1985; Best and Henry 1994).

Despite its importance, aspects such as the origin and domestication of the cassava and phylogenetic relationships with other species of the genus have not been elucidated. Linguistic, ethnological, archeological, taxonomic and geographic evidence suggest that the crop had many points of initial cultivation. Rogers and Appan (1973) proposed that, of the 98 species they described, the Central American species M. aesculifolia (H.B.K.) Pohl is the closest wild relative. M. esculenta Crantz subsp. flabellifolia (Pohl) Ciferri was regarded as a synonym of cassava; the species $M$. tristis Muell. Arg. and M. peruviana Muell. Arg. were placed in different sections of the genus. Allem (1987) disagreed, suggesting $M$. tristis as the species most similar to cassava. He later reported (1994 a, b) finding wild forms of the cultivated species in north-eastern Brazil, regarding the glabrous form as M. esculenta subsp. flabellifolia; the pubescent variety as $M$. esculenta Crantz subsp. peruviana (Muell. Arg.) Allem; and M. tristis as 
a synonym, morphologically indistinguishable from M. esculenta subsp. flabellifolia.

Allem's propositions have since been challenged by suggestions that the re-classified wild forms may have been escapes from cassava crops (Renvoize 1972; Bertram 1993). The appearance of swollen nodes in these plants cast doubt on their nature as true wild relatives, as this character was considered to be an indirect result of artificial selection for efficient vegetative reproduction (Jennings 1976, cited by Bertram 1993). The question thus remains: is cassava the result of domestication of these wild populations, or are they escapes from cultivated material?

Molecular markers have recently been employed to help resolve some of these taxonomic and phylogenetic questions. Bertram (1993) analyzed 14 Manihot species from North and Central America, together with land races and improved varieties of cassava from different regions, performing a cladistic analysis of RFLP (restriction fragment length polymorphism) variation in chloroplast (cp) and ribosomal (r) DNA. He proposed that M. aesculifolia was most similar to cassava, together with M. carthaginensis (Jacquin) Muell. Arg. Fregene et al. (1994), analyzing RFLPs of cpDNA and rDNA of 29 accessions of wild species and cultivated varieties, showed that $M$. tristis and $M$. esculenta subsp. flabellifolia are also very close to, but divergent from, cassava. They suggested that cassava was more likely to have been domesticated from a complex of these species than from a hybridization event between them. But because molecular studies have rarely treated Central American species together with those of South America, a lack of consensus still exists on the origin of cassava, and the degree of its relationships with other Manihot species.

A new type of marker is now available to help address these questions. AFLP (amplified fragment length polymorphism) analysis is a technique through which selected restriction fragments from the digestion of total plant DNA are amplified by the polymerase chain reaction (Vos et al. 1995). The resulting DNA fingerprint provides a large number of genetic markers; and the multiplex ratio, defined as the number of information points analyzed per experiment, is much higher than for other types of markers, such as RFLP, RAPD (randomly amplified polymorphic DNA) or SSRP (simple sequence repeat polymorphism) (Powell et al. 1996).

We used the AFLP technique to analyze the five wild forms mentioned above as close relatives or ancestors of cassava, a distant species (M. brachyloba Mueller von Argau), and a representative sample of the genetic diversity available in the crop. Based on our results, we revised hypotheses on the ancestry and origin of cassava.

\section{Materials and methods}

Plant materials

A total of 105 genotypes were evaluated, comprising 35 landraces of cassava, three bred cassava lines, and 67 individuals from six additional taxa: $M$. aesculifolia, M. carthaginensis, M. brachyloba, M. tristis, M. esculenta subsp. flabellifolia and M. esculenta subsp. peruviana (Table 1). The landraces were selected from the larger core collection of cassava germ plasm conserved at CIAT, Cali, Colombia, using geographic, morphological and biochemical parameters (Hershey et al. 1994).

\section{DNA extraction}

Fresh young leaves were harvested from each genotype on liquid nitrogen and maintained at $-80^{\circ} \mathrm{C}$. DNA was extracted, using either the method of Dellaporta et al. (1983), with 3-4 g of leaf tissue, or the ORSTOM method, with freshly harvested and dried leaf tissue (at $48^{\circ} \mathrm{C}$ for $24 \mathrm{~h}$ ) (C. Colombo, in preparation).

\section{AFLP method}

The AFLP protocol followed was that described by Vos et al. (1995), with slight modifications (Tohme et al. 1996). Primary template was prepared by the simultaneous digestion of DNA with EcoRI and $M s e I$ and subsequent ligation of asymmetric quantities of enzymespecific adapters. The amount of information obtained by AFLP is a factor of the number of selective nucleotides employed, and the size and complexity of the genome being analyzed. Trials were conducted on two Manihot accessions, with 20 combinations of first- and second-round primers (see Table 2) to identify successful combinations of selective nucleotides, taking into account Manihot's genome size of between 6.93 and $8.30 \times 10^{8}$ base pairs (Arumuganathan and Earle 1991) and recommendations made by Lin and Kuo (1995). DNA samples of eight genotypes were obtained independently, and in duplicate, with each of the two extraction methods. These samples were evaluated to ensure robustness and reproducibility of the AFLP protocol.

Following these preliminary trials, the entire set of plant materials was analyzed, using $A$ and $G$ as selective nucleotides (EcoRI primer $+\mathrm{A}$, and MseI primer $+\mathrm{G}$, respectively) for pre-amplification, and the two second-round primer combinations (EcoRI + $\mathrm{AAC} \times \mathrm{Mse} \mathrm{I}+\mathrm{GTA}$, and $E c o \mathrm{RI}+\mathrm{ACA} \times \mathrm{Mse} \mathrm{I}+\mathrm{GTA})$. Radio active amplification products [from labelling the EcoRI primer in the second round of amplification with $\left.\left[{ }^{32} \mathrm{P}\right] \gamma \mathrm{dATP}\right]$ were sizefractionated on $6 \%$ polyacrylamide denaturing gels on a Sequi-Gen (BioRad) sequencing apparatus. Electrophoresis was carried out for $2 \mathrm{~h}$ in $1 \times \mathrm{TBE}$ at $40 \mathrm{~V} / \mathrm{cm}$ and $45^{\circ} \mathrm{C}$. The gels were covered with Saran Wrap, dried under vacuum for $1 \mathrm{~h}$ at $80^{\circ} \mathrm{C}$, and exposed for 16 $\mathrm{h}$ on X-ray films (Kodak X-omat LS) for autoradiography.

\section{Data analysis}

AFLPs from the two primer combinations were registered in terms of the presence or absence of bands in each of the 105 accessions evaluated. The results were converted into a similarity matrix, based on the index of Nei and $\mathrm{Li}$ (1979).

The similarity matrix was analyzed, using the computer program NTSYS (version 1.8; Rohlf 1994). Dendrograms were constructed by employing the option TREE, and the UPGMA (unweighted pair grouping method of averages) method of Sneath and Sokal (1973). A correlation index was calculated between the similarity 
Table 1 Manihot germ plasm selected for AFLP analysis

\begin{tabular}{|c|c|c|c|c|c|c|}
\hline Manihot species & Accession $\operatorname{code}^{\mathrm{a}}$ & $\begin{array}{l}\text { No. of } \\
\text { individuals }\end{array}$ & $\begin{array}{l}\text { Country } \\
\text { of origin }\end{array}$ & $\begin{array}{l}\text { Manihot esculenta } \\
\text { accession code }^{\mathrm{a}}\end{array}$ & $\begin{array}{l}\text { Country of } \\
\text { origin }\end{array}$ & Common name \\
\hline \multirow[t]{7}{*}{ M. aesculifolia } & AES 002 & 1 & Mexico & M ARG 11 & Argentina & Duro do Valle 30 \\
\hline & AES 404-004 & 1 & Mexico & M BOL 3 & Bolivia & Rosada de Bolivia \\
\hline & WU 26 AES 2 & 1 & Mexico & M BRA 12 & Brazil & $--^{\mathrm{c}}$ \\
\hline & WU 25 AES 6 & 1 & Mexico & M BRA 97 & Brazil & Saracura II \\
\hline & WU 24 AES 7 & 1 & Mexico & M BRA 110 & Brazil & Pangola \\
\hline & WU 32 AES 4 & 1 & Mexico & M BRA 881 & Brazil & Branca de Sta. Catarina \\
\hline & WU 27 AES 5 & 1 & Mexico & M BRA 885 & Brazil & Jabarú \\
\hline \multirow[t]{3}{*}{ M. brachyloba } & BLO 001 & 1 & - & M BRA 900 & Brazil & Mandim Branca \\
\hline & BLO 401 & 1 & Colombia & M BRA 931 & Brazil & Enganha Ladrão \\
\hline & BLO 402 & 1 & Colombia & M COL 1468 & Brazil & Sip24-2 Mantiqueira \\
\hline \multirow[t]{14}{*}{ M. carthaginensis } & CTH 005 & 1 & Colombia & M COL 22 & Colombia & Uvita \\
\hline & СТH 011 & 1 & Colombia & M COL 1438 & Colombia & Llanera \\
\hline & СТH 012 & 1 & Colombia & M COL 1522 & Colombia & Algodonera Amarilla \\
\hline & СТH 121 & 1 & Colombia & M COL 2061 & Colombia & Regional Morada \\
\hline & СТH 164 & 1 & Colombia & M COL 2066 & Colombia & Chiroza Gallinaza \\
\hline & CTH 246 & 1 & Colombia & M COL 2215 & Colombia & Venezolana 1 \\
\hline & CTH 315 & 1 & Colombia & HMC 1 & Colombia & - \\
\hline & СТH 409 & 2 & Colombia & M CR 32 & Costa Rica & Yuca Mangi \\
\hline & CTH 411 & 1 & Colombia & M CUB 51 & Cuba & Pinera \\
\hline & CTH 414 & 1 & Colombia & M CUB 74 & Cuba & Señorita \\
\hline & СТH 415 & 5 & Colombia & M ECU 41 & Ecuador & De Tres Meses \\
\hline & CTH 416 & 1 & Colombia & M ECU 82 & Ecuador & Blanca \\
\hline & CTH 417 & 6 & Colombia & M IND 33 & Indonesia & No. $734-5$ \\
\hline & CTH Z & 1 & - & M MAL 2 & Malaysia & Black Twig \\
\hline \multirow{5}{*}{$\begin{array}{l}\text { M. esculenta } \\
\text { subsp. } \\
\text { flabellifolia }\end{array}$} & ESC-FLA 423 & 2 & Brazil & M MAL 48 & Malaysia & Red Twig \\
\hline & ESC-FLA 427 & 2 & Brazil & M MEX 59 & Mexico & - \\
\hline & ESC-FLA 428 & 2 & Brazil & M PAN 51 & Panama & - \\
\hline & ESC-FLA 430 & 1 & Brazil & M PAR 110 & Paraguay & Tacuara Sayyu \\
\hline & ESC-FLA 438 & 2 & Brazil & M PTR 19 & Puerto Rico & No. 9588 \\
\hline \multirow{7}{*}{$\begin{array}{l}\text { M. esculenta } \\
\text { subsp. } \\
\text { peruviana }\end{array}$} & ESC-PER 407 & 2 & Brazil & M VEN 45 & Venezuela & - \\
\hline & ESC-PER 411 & 2 & Brazil & M COL 1505 & Venezuela & - \\
\hline & ESC-PER 412 & 2 & Brazil & CM 2177-2 & CIAT $^{\mathrm{d}}$ & Hybrid \\
\hline & ESC-PER 413 & 2 & Brazil & CM 3306-9 & CIAT $^{\mathrm{d}}$ & Hybrid \\
\hline & ESC-PER 414 & 2 & Brazil & TMS 30572 & IITA $^{\mathrm{e}}$ & Hybrid \\
\hline & ESC-PER 415 & 2 & Brazil & & & \\
\hline & ESC-PER 417 & 2 & Brazil & & & \\
\hline \multirow[t]{4}{*}{ M. tristis } & TST-002 & 1 & - & & & \\
\hline & TST-008 & 1 & - & & & \\
\hline & TST-009 & 1 & - & & & \\
\hline & TST-011 & 1 & - & & & \\
\hline
\end{tabular}

${ }^{a}$ Manihot species were collected as true-seed populations

${ }^{\mathrm{b}}$ Cassava accessions are maintained as vegetative clones

$c_{-}=$as used throughout field, indicates "no data"

${ }^{\mathrm{d}}$ Centro Internacional de Agricultura Tropical, based in Colombia

e International Institute of Tropical Agriculture, based in Nigeria

matrices resulting from the two different primer combinations to analyze the complementary or redundancy of the information.

The means of all pairwise similarities between the individuals within each of the principal clusters identified by UPGMA were compared, using Duncan's multiple range test. Similarities between individuals comprising all pairwise combinations of species were also calculated to determine the means and standard deviations of interspecific similarities. Multiple correspondence analysis (MCA) was conducted to evaluate the contribution of the specific active variables (AFLP products) to the variation observed among genotypes, by employing the CORRESP option of SAS (version 6-11; 1989).

\section{Morphological characterization}

Except for several accessions of M. aesculifolia, which were available only as leaf samples, the germ plasm included in this study was characterized morphologically, using a set of descriptors comprised 
Table 2 Informativeness of 20 combinations of selective primers used to detect AFLP between two Manihot genotypes (ESC-FLA 423-6 and ESC-PER 412-2). In all cases, pre-amplification was carried out with EcoRI $+\mathrm{A}$ and $\mathrm{Mse} \mathrm{I}+\mathrm{G}$ primers. Total number of bands and percentage of polymorphism are as observed for the two genotypes analyzed

\begin{tabular}{|c|c|c|c|c|c|c|c|c|}
\hline \multirow[t]{3}{*}{ EcoRI primer } & \multicolumn{8}{|c|}{ MseI primer } \\
\hline & \multicolumn{2}{|l|}{ GTA } & \multicolumn{2}{|l|}{$\mathrm{GCG}$} & \multicolumn{2}{|l|}{ GAC } & \multicolumn{2}{|l|}{ GGT } \\
\hline & $\begin{array}{l}\text { Bands } \\
\text { (no.) }\end{array}$ & $\begin{array}{l}\text { Polymorphs } \\
(\%)\end{array}$ & $\begin{array}{l}\text { Bands } \\
\text { (no.) }\end{array}$ & $\begin{array}{l}\text { Polymorphs } \\
(\%)\end{array}$ & $\begin{array}{l}\text { Bands } \\
\text { (no.) }\end{array}$ & $\begin{array}{l}\text { Polymorphs } \\
(\%)\end{array}$ & $\begin{array}{l}\text { Bands } \\
\text { (no.) }\end{array}$ & $\begin{array}{l}\text { Polymorphs } \\
(\%)\end{array}$ \\
\hline $\mathrm{AAC}$ & $45^{\mathrm{a}}$ & $44^{\mathrm{a}}$ & 37 & 38 & 35 & 51 & 44 & 36 \\
\hline AGT & 33 & 48 & 30 & 47 & 36 & 22 & 34 & 68 \\
\hline $\mathrm{ACA}$ & $44^{\mathrm{a}}$ & $61^{\mathrm{a}}$ & 47 & 28 & 34 & 59 & 30 & 60 \\
\hline $\mathrm{AT}$ & 87 & 40 & 24 & 29 & 56 & 41 & 84 & 49 \\
\hline
\end{tabular}

a Primer combinations selected for analysis of the Manihot germ-plasm set

$\mathrm{b}_{-}=$"no data"

of 38 characters, both vegetative (stem, leaf, petiole and stipules) and reproductive (flower, fruit and seed).

\section{Results}

AFLP provides a high information content for Manihot species

A comparison of information content and the resolution of amplification products from 20 combinations of primers revealed between 24 and 87 amplification products per individual and $22 \%$ to $74 \%$ polymorphic bands between the two individuals analyzed (Table 2). Three primer pairs employing $(E c o R I)+2$ and $(M s e \mathrm{I})+3$ selective nucleotides revealed a larger number of AFLP products in the germ plasm than the $+3 /+3$ combinations, but these were generally less polymorphic. Among the $+2 /+3$ combinations, the generation of the lowest number of AFLP products with MseI primer $+\mathrm{GCG}$ is consistent with expectations based on sequence context. The primer combinations EcoRI + $\mathrm{AAC} \times$ MseI + GTA, and EcoRI + ACA $\times$ MseI + GTA were chosen as the most informative, and applied to the complete set of germ-plasm accessions.

Analysis of the 105 genotypes presented a total of 139 AFLP bands for the first primer combination, and 165 bands for the second, when bands from all individuals were considered. The number of bands obtained per individual ranged from 17 to 51, confirming the high multiplex ratio obtainable with this type of marker (Fig. 1). Only two bands revealed by analysis with each primer combination were monomorphic in the germ-plasm set, demonstrating a polymorphism of $98.6 \%$, a higher rate than that obtained with other marker types, using different plant materials: isozyme analysis of cultivated and wild Manihot species showed $55 \%-58 \%$ polymorphism (Lefévre and Charrier 1993), RAPD patterns 31\% (Carvalho et al. 1994), and RFLPs 6\%-98\% (Bertram 1993; Haysom et al. 1994).
The matrices of genetic similarity estimates, based on AFLP patterns from the two separate primer combinations, were highly correlated $(r=0.91)$. The analysis permitted the unique identification of each individual analyzed, indicating that the collection does not contain genetic duplicates, and facilitated analysis of the distribution of genetic diversity among accessions and species.

\section{Cluster analysis}

Figure 2 depicts the clustering of Manihot accessions into eight groups of individuals that correspond largely to prior taxonomic classification. Discrete groups were formed for the species $M$. aesculifolia, M. brachyloba and $M$. carthaginesis (clusters 1, 2 and 3, respectively), and cassava (M. esculenta, cluster 8). Most accessions pertaining to $M$. esculenta subspp. flabellifolia and peruviana fell into a mixed cluster (7). Three smaller groups were formed by two pairs of individuals adapted to high altitudes, the $M$. esculenta subspecies (4 and 5) and M.tristis (6).

The accessions representing cassava appear as a compact group (8), with greater similarity among its members than in the next cluster (7). Because cluster 7 comprised a mixture of $M$. esculenta subspp. flabellifolia and peruviana accessions, these two subspecies were pooled into a single group for subsequent analyses.

Mean similarities between pairs of individuals within the six resulting groups were significantly different $(P<0.05)$, according to Duncan's multiple range test (Table 3). As expected, intraspecific similarity (Table 3, diagonal) was greater in all cases than interspecific (Table 3, upper triangle).

\section{Multiple correspondence analysis}

The multiple correspondence analysis (MCA; Fig. 3 a) portrayed $M$. aesculifolia, M. carthaginesis and 
Fig. 1 Autoradiograph showing AFLP detected in a subset of Manihot germ plasm with the second-round selective primer combination EcoRI +

AAC $\times$ Mse I + GTA. Arrows indicate putative species-specific bands for $M$. aesculifolia, $M$. brachyloba and M. carthaginensis

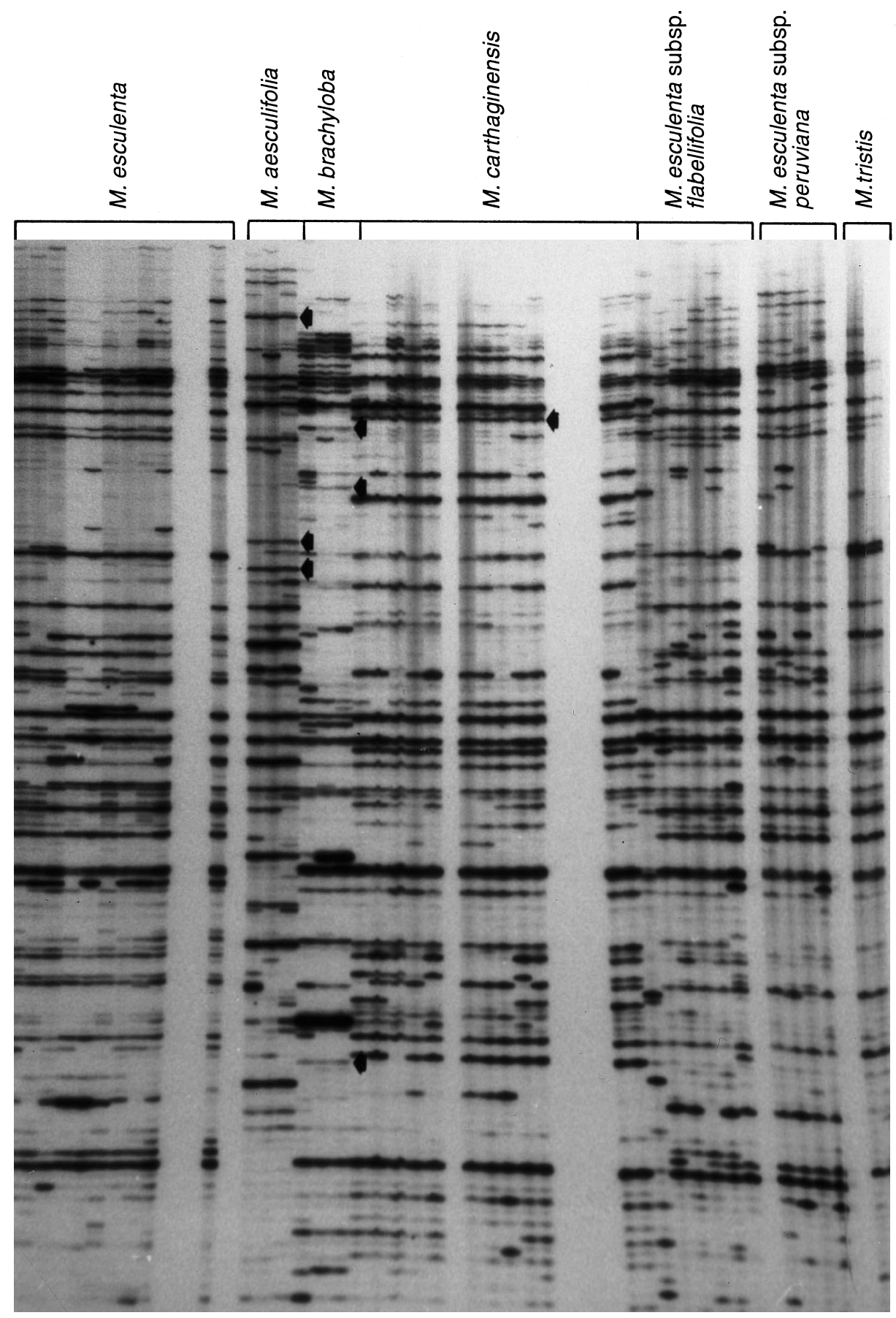

M. brachyloba as discrete groups that are separate from the other accessions. M. esculenta appears as a compact group with accessions of $M$. tristis and the two $M$. esculenta subspecies nearby.

A separate multiple correspondence analysis was performed on the 69 genotypes representing the two $M$. esculenta subspecies, $M$. tristis and M. esculenta, to improve resolution of the structure of diversity within these taxa (Fig. 3 b). The first dimension of MCA was effective in separating M. esculenta, as a single compact group, from the other taxa. The second dimension further distinguished M. tristis from the two M. esculenta subspecies. The third dimension separated a "pure" group of five accessions of the M. esculenta subsp. peruviana from the other individuals of the $M$. esculenta subspecific complex. The "pure peruviana" 


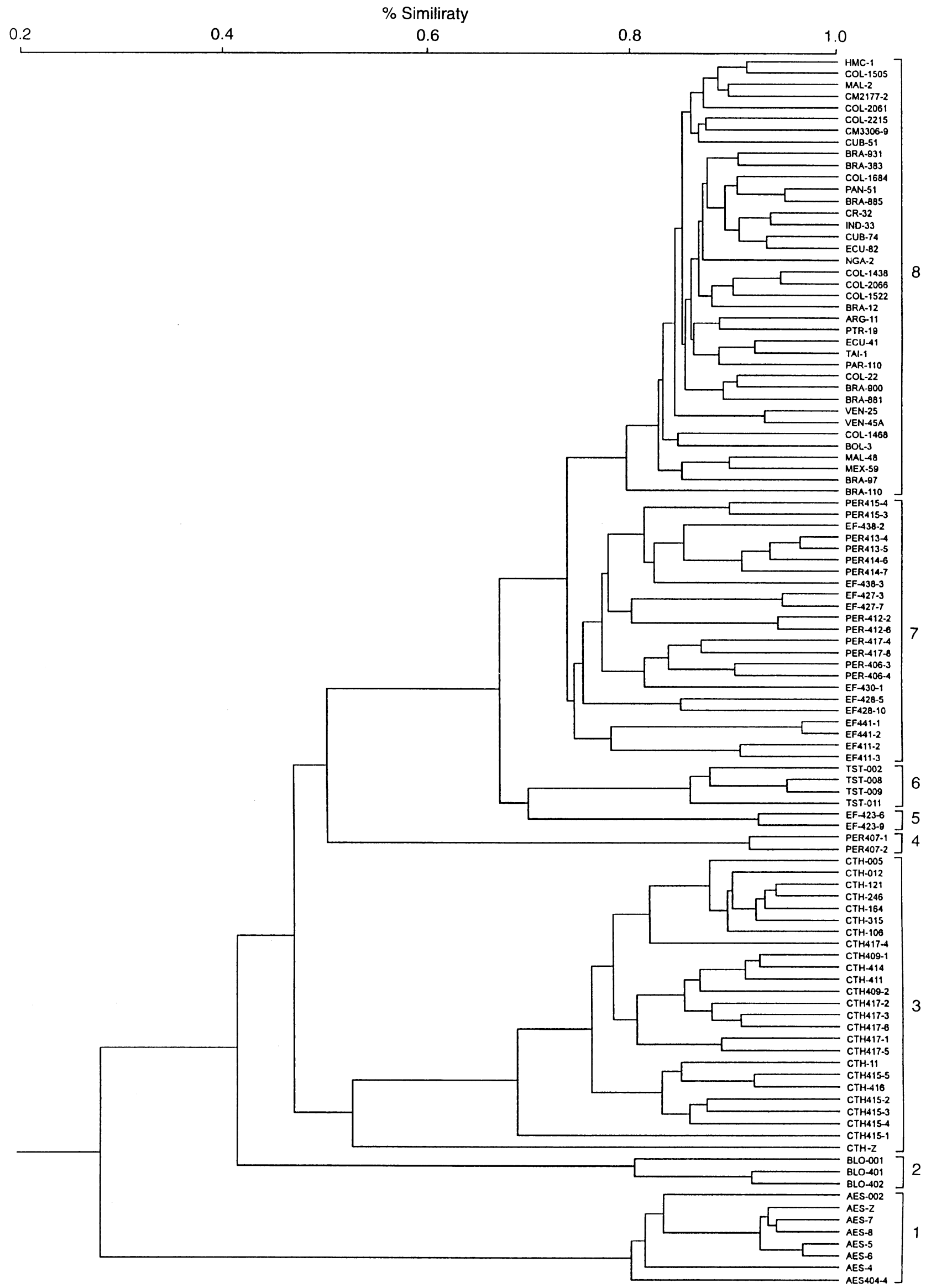


Table 3 Genetic similarity values (mean \pm SD) between (upper triangle) and within (diagonal) groups of Manihot germ plasm, based on all pairwise similarities between individuals. Different letters on the diagonal indicate significant differences $(P<0.05)$ by Duncan's multiple range test

\begin{tabular}{lllllll}
\hline Group $^{\mathrm{a}}$ & ESC $(n=38)$ & AES $(n=8)$ & BLO $(n=3)$ & CTH $(n=25)$ & TST $(n=4)$ & $\begin{array}{l}\text { ESCFLA-PER } \\
(n=14)\end{array}$ \\
\hline ESC & $0.85 \pm 0.03 \mathrm{ab}$ & $0.31 \pm 0.03$ & $0.41 \pm 0.02$ & $0.47 \pm 0.03$ & $0.65 \pm 0.03$ & $0.70 \pm 0.11$ \\
AES & & $0.86 \pm 0.06 \mathrm{a}$ & $0.26 \pm 0.02$ & $0.26 \pm 0.02$ & $0.27 \pm 0.02$ & $0.27 \pm 0.05$ \\
BLO & & $0.84 \pm 0.07 \mathrm{ab}$ & $0.43 \pm 0.04$ & $0.41 \pm 0.03$ & $0.40 \pm 0.05$ \\
CTH & & & $0.77 \pm 0.09 \mathrm{cb}$ & $0.45 \pm 0.04$ & $0.46 \pm 0.06$ \\
TST & & & & $0.88 \pm 0.04 \mathrm{a}$ & $0.67 \pm 0.11$ \\
ESC FLA-PER & & & & & $0.70 \pm 0.15 \mathrm{c}$ \\
\hline
\end{tabular}

${ }^{\mathrm{a}} \mathrm{ESC}=M$. esculenta $; \mathrm{AES}=M$. aesculifolia $; \mathrm{BLO}=M$. brachyloba $; \mathrm{CTH}=M$. carthaginensis; $\mathrm{TST}=M$. tristis; $\mathrm{ESCFLA-PER}=$ M. esculenta subspp. flabellifolia and peruviana

group came from disturbed Amazonian forest of Mato Grosso, Brazil. The remaining group of subspecific accessions was more dispersed, reflecting a structure of subgroups that corresponded with their respective habitats, geographical coordinates and altitudes.

The MCA also highlighted AFLPs that are specific to the accessions of each of the wild species (Fig. 1). With the first and second primers, 6 and 9, 4 and 6, and 1 and 0 , putative species-specific bands were identified in M. esculenta, M. brachyoba, and M. carthaginensis, respectively. In addition, the latter two species were each distinguished by the exclusive absence of certain bands. MCA also facilitated the identification of AFLPs that reflect species heterogeneity by their exclusive presence in individuals of putative infraspecific gene pools, which should therefore be further sampled and considered in conservation and classification efforts.

Considering only the reduced set of germ plasms (Fig. 3 b), 52 bands were found in both M. esculenta subspecies, sometimes in M. tristis but absent from cassava. Furthermore, 21 AFLP bands were present in cassava while absent from the rest of the group, suggesting a larger pool of alleles for the two M. esculenta subspecies and M. tristis than for M. esculenta.

Supporting morphological evidence for inferences made from AFLP analysis

Morphologically, no significant differences were found between the two subspecific taxa. The presence of pubescence on ovaries and young fruits, used in Allem's

Fig. 2 Dendrogram drawn from the UPGMA analysis of Nei-Li estimates of genetic similarity based on AFLP analysis with two $+1 /+3$ primer combinations. The eight clusters shown are discussed in the text. $1=(\mathrm{AES}) M$. aesculifolia; $2=(\mathrm{BLO}) M$. brachyloba; $3=(\mathrm{CTH})$ M. carthaginensis; $4=($ PER $)$ M. esculenta subsp. peruviana, higher altitude; $5=(\mathrm{EF}) \mathrm{M}$. esculenta subsp. flabellifolia higher altitude; $6=(\mathrm{TST}) M$. tristis; $7=(\mathrm{EF}$ and PER $)$ M. esculenta subspp. flabellifolia and peruviana; $8=$ M. esculenta, i.e. cassava
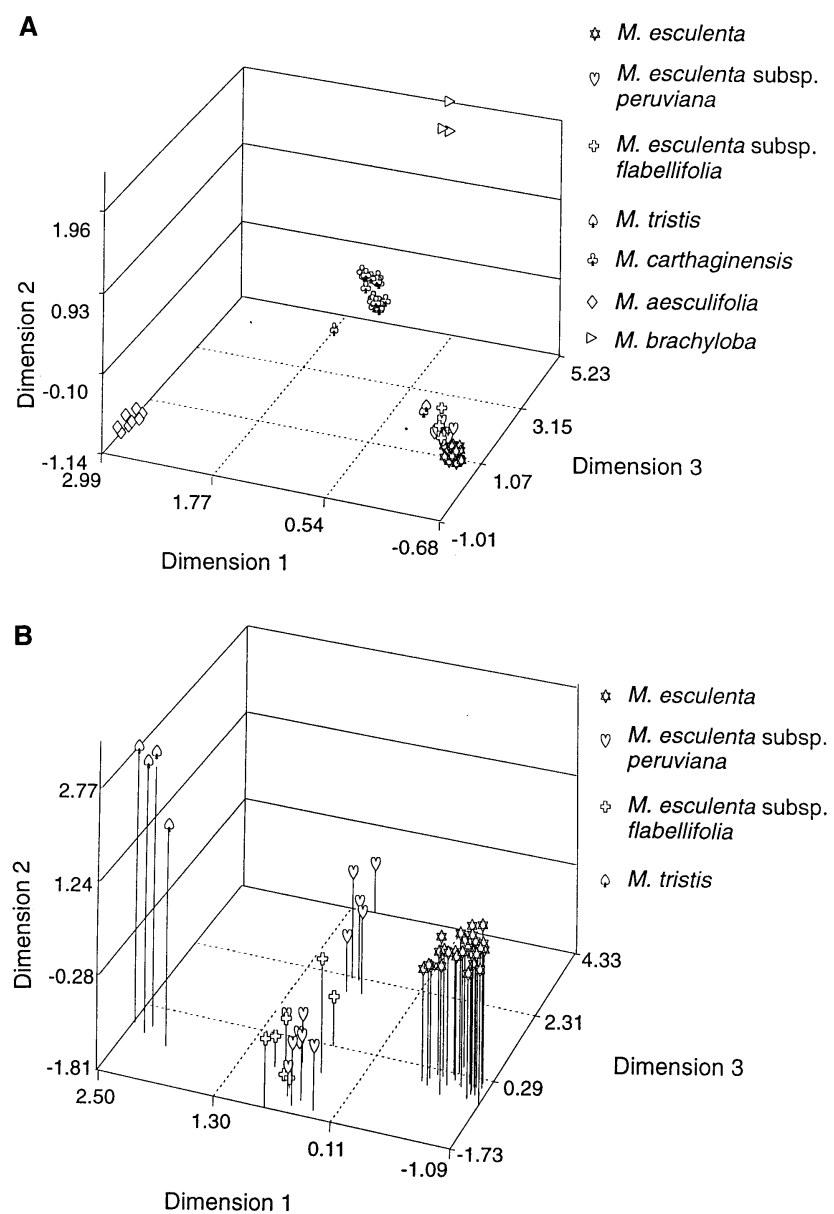

Fig. 3 Three principal axes of variation obtained by multiple correspondence analysis of AFLP among 105 samples of seven groups (A) of Manihot germ plasm resolved with two primer combinations; (B) shows a higher resolution of 69 samples of four groups

(1994 a, b) classification, could not consistently differentiate the subspecies. For example, four genotypes originating from accessions classified as M. esculenta subsp. flabellifolia presented abundantly pubescent ovaries; and, reciprocally, 15 plants from accessions of M. esculenta subsp. peruviana had glabrous ovaries. We 
have also observed this character to be variable in $M$. brachyloba. Observations were repeated over time to account for the character's transitory nature, but it may be plastic in contrasting environments.

For the character of swollen nodes, morphological evaluation showed that, while leaf scars and the associated enlarged nodes along the plants' woody stems were prominent in all cassava accessions, they were not marked, or else only slightly prominent in the subspecific taxa. This character varies according to the degree of habitat disturbance and variation of the ecological factors (Rogers and Appan 1973; Allem 1994 a). Thus, we consider both "pubescent ovaries" and "swollen nodes" as descriptors of limited confidence, with little bearing on taxonomic status.

No significant morphological differences were found among the accessions of $M$. tristis and $M$. esculenta subsp. flabellifolia in the collection. Two characters petiole attachment and pubescence of vegetative parts have been used to distinguish among subspecies of M. tristis (Rogers and Appan 1973). The M. tristis accessions in this collection present non-peltate leafpetiole junctures with pubescence only on leaf buds. In its turn, the subspecies flabellifolia was variable for peltate and non-peltate leaves, with the leaf juncture ranging from 0.5 to $2.0 \mathrm{~cm}$ from the leaf base. The subspecies also varied between totally glabrous and pubescent vegetative parts. These characters therefore do not seem useful for separating these taxa.

For those genotypes that differed from their conspecifics according to the AFLP analysis, morphological evaluation did not always support the distinction. For example, the accession PER 407, distinct from other accessions of the subspecies in the cluster analysis (Fig. 2), is itself variable for the principal character used to define the group: one of the two genotypes analyzed from this population had pubescent ovaries and the other did not. In contrast, the outlying accession of M. carthaginensis, CTH Z, showed a fruit surface character that differs from those described for the species. AFLP analysis confirms its distinction from the majority of Colombian accessions. As accurate passport data are not available for this accession, we assume that it represents either a subgene pool from northern Colombia or a natural hybrid.

\section{Discussion and conclusions}

We found AFLP analysis to be an effective and efficient means of providing quantitative estimates of genetic similarities related to the distribution of variability within and among previously recognized taxa of the relatively large and possibly taxonomically inflated genus Manihot. AFLPs also identified unique genetic diversity present in the wild relatives of the crop M. esculenta.

\section{Interspecific similarities in Manihot}

As shown in Fig. 2 and Table 3, M. aesculifolia was the most distant species from cassava in this study, having the lowest mean interspecific similarity (0.307), followed by $M$. brachyloba and $M$. carthaginensis. This outcome contradicts earlier reports that M. aesculifolia is the closest relative of cassava. M. aesculifolia was also the most distant species (mean interspecific similarities $0.258-0.274$ ) from the remaining taxa.

Higher degrees of similarities (means 0.654-0.700) were observed between the taxa classified as $M$. esculenta, M. tristis, M. esculenta subsp. flabellifolia, and M. esculenta subsp. peruviana. The finding that the mixed group of subspecies is most similar to cassava (0.700) agrees with Allem's (1994 a, b) proposal that these con-specific taxa are the wild forms most closely related to the crop, and also with the classification by Fregene et al. (1994) into the same group by cpDNA and rDNA analysis.

The species relationships illustrated by AFLP are supported by preliminary data on crossability. CIAT recently hybridized some of these groups to test for compatibility and gene flow, and so generate possible benefits for cassava breeding. Literally thousands of seeds were obtained from 16 successful cross combinations - including reciprocal crosses - between cassava and M. esculenta subsp. flabellifolia, but only five seeds were obtained from two crosses between cassava and M. aesculifolia. Similar results were obtained with crosses between cassava and another Central American species, M. chlorosticta Standley and Goldman, which yielded between 1 and 148 seeds in 14 successful combinations with the wild species as the female parent, and with the seeds presenting substantial problems of dormancy.

\section{Intraspecific variability in Manihot}

As a whole, the subspecies complex showed the lowest intraspecific similarity value (0.700) of the taxa studied (Table 3). It forms a diverse set of germ plasms of considerable genetic heterogeneity corresponding to ecogeographic gene pools.

The intermixing of accessions of the two subspecies (Fig. 2) reflects their sympatric distribution and the tenuous morphological distinction used to separate them. For example, Allem (1994 b) proposed that the pubescence found on flowers, ovaries, and young fruits differentiated $M$. esculenta subsp. peruviana as a "wild pubescent form" of M. esculenta. But we found this character to be variable for each subspecies. The sympatric distribution of the wild forms of cassava (Allem $1994 \mathrm{~b}$ ), and the predominance of allogamy and pollination by insects in the Manihot genus, also make the pubescent character unlikely to be constant and, therefore, unreliable for distinguishing taxa. 
The two individuals of each M. esculenta subspecies that separated in the cluster analysis (groups 4 and 5) from the mixed group (7, Fig. 2) were from the upper extreme of the altitudinal ranges reported for the respective taxa in Brazil (Allem 1995). The two outlying representatives of the subspecies flabellifolia do not show morphological differences from the accessions in the main cluster, but originate from the higher areas of the Brazilian cerrados (dry semi-caducifolious forest, mixed with pastures), which are characterized by a subhumid to dry climate. Most of the other accessions are from disturbed Amazonian forest, where climates are humid to very humid.

Another taxon presenting a wide range of pairwise genetic similarities was $M$. carthaginensis. Heterogeneity was clearly related to distances between Colombian accessions and one accession (CTH Z) of unknown origin. Individual comparisons of similarities ranged from 0.95 among accessions from the same site to 0.53 between Colombian representatives and $\mathrm{CTH}$ $\mathrm{Z}$, thus suggesting the existence of different gene pools within this species.

Despite the almost equal sample sizes analyzed for M. brachyloba and M. tristis, the range of similarities among individuals is notably greater in the former species. We have identified populations of M. brachyloba in distinct ecological habitats in Colombia, but we could not analyze their possible genetic differentiation because they survived poorly under ex situ conditions. Unfortunately, the more distant accession of M. brachyloba studied here lacks passport data.

Patchiness of species diversity and the existence of different gene pools within species have implications for future strategies of germ plasm sampling for conservation purposes. This is particularly relevant to the present assessment of $M$. aesculifolia, M. carthaginensis and $M$. brachyloba, which are variously distributed in several countries of Central and South America. M. brachyloba is the only species reported to be distributed in both South and Central America (Rogers and Appan 1973), and M. carthaginensis may be the only species distributed in Mexico and Brazil (Bertram 1993; Allem 1995). New introductions of $M$. carthaginensis from Brazil are now available, and additional collections are planned to expand the analysis.

The present work shows that the complex formed by the M. esculenta subspecies flabellifolia and peruviana possesses unique diversity relative to a broad sample of cassava germ plasm. This argues against these subspecies being escapes from cultivation of the crop. To strengthen this argument, the study should be complemented by more intensive sampling of landraces in the regions where the subspecies are found, as well as by complementary types of genetic analysis such as cladistic phylogeny.

The species-specific presence or absence of particular AFLP products may have implications of prac- tical importance. Broader sampling is needed to confirm the extent of conservation of these bands in the respective species. It would then be useful to determine the genomic organization of these products to decide, for example, if they represent low copy number or repeated DNA sequences, and how they are arranged. Once the genomic or taxonomic distribution of these sequences is known, they may serve as markers for introgression or for identifying and classifying germ plasm.

Acknowledgements We thank D. O. González and G. Gallego for introducing us to AFLP analysis, and the assistants at the CIAT Cassava Program for help with the care and evaluation of plants in the field. We are also grateful to Washington University for the donation of dried leaf samples of $M$. aesculifolia collected by R. Bertram, and to Elizabeth de Páez for editorial assistance.

\section{References}

Allem AC (1987) Manihot esculenta is a native of the neotropics. Plant Genet Resourc Newsl (Int Board Plant Genet Resourc) 71: $22-24$

Allem AC (1994 a) Manihot germ plasm-collecting priorities. In: International network for cassava genetic resources. Report of the First Meeting of the International Network for Cassava Genetics Resources, CIAT, Cali, Colombia, 18-23 August. IPGRI, Rome, International Crop Network Series No. 10, pp $87-110$

Allem AC (1994 b) The origin of Manihot esculenta Crantz (Euphorbiaceae). Genet Res Crop Evol 41:133-150

Allem AC (1995) Collection of wild strains of cassava in Brazil: fourth progress report. IPGRI and CENARGEN/EMBRAPA, Brasília

Arumuganathan K, Earle ED (1991) Nuclear DNA content of some important plant species. Plant Mol Biol Rep 9: $208-218$

Bertram RB (1993) Application of molecular techniques to genetic resources of cassava (Manihot esculenta Crantz, Euphorbiaceae): interspecific evolutionary relationships and intraspecific characterization. PhD dissertation, University of Maryland

Best R, Henry G (1994) Cassava: towards the year 2000. In: International network for cassava genetic resources. Report of the First Meeting of the International Network for Cassava Genetics Resources, CIAT, Cali, Colombia, 18-23 August. IPGRI, Rome, International Crop Network Series No. 10, pp $3-11$

Carvalho LJCB, Buso GSC, Brandoni C, Allem AC, Fukuda WMG, Sampaio MJAM (1994) Study on interspecific evolutionary relationships and intraspecific characterization of cassava germplasm at CENARGEN/EMBRAPA. In: Cassava biotechnology network. Proc 2nd Scientific Meeting, 22-26 August, Bogor, Indonesia. CBN, CR, FC, AARD, and CIAT, Cali, Colombia, Working document no. 150, 2 vols, pp 163-173

Cock JH (1985) Cassava: new potential for a neglected crop. Westview Press, Boulder, Colorado

Dellaporta SL, Wood J, Hicks JR (1983) A plant DNA minipreparation: version II. Plant Mol Biol Rep 1:19

Fregene MA, Vargas J, Angel F, Tohme J, Asiedu RA, Akorada MO, Roca WM (1994) Chloroplast DNA and nuclear ribosomal DNA variability in cassava (Manihot esculenta Crantz) and its wild relatives. Theor Appl Genet 89:719-727

Haysom HR, Chan TLC, Hughes MA (1994) Phylogenetic relationships of Manihot species revealed by restriction fragment length polymorphism. Euphytica $76: 227-234$ 
Hershey C, Iglesias C, Iwanaga M, Tohme J (1994) Definition of a core collection for cassava. In: International network for cassava genetic resources. Report of the First Meeting of the International Network for Cassava Genetics Resources, CIAT, Cali, Colombia, 18-23 August. IPGRI, Rome, International Crop Network Series No. 10, pp $145-156$

Lefévre F, Charrier A (1993) Isozyme diversity within African Manihot germplasm. Euphytica 66:73-80

Lin JJ, Kuo J (1995) AFLP ${ }^{\mathrm{TM}}$ : a novel PCR-based assay for plant and bacterial DNA fingerprinting. Focus 17:66-70

Nei M, Li W (1979) Mathematical model for studying genetic variation in terms of restriction endonucleases. Proc Natl Acad Sci USA 76:5269-5273

Powell W, Morgante M, Andre C, Hanafey M, Vogel J, Tingey S, Rafalski A (1996) The comparison of RFLP, RAPD, AFLP and SSR (microsatellite) markers for germplasm analysis. Mol Breed $3: 225-238$
Renvoize BS (1972) The area of origin of Manihot esculenta as a crop plant - a review of the evidence. Econ Bot 26:352-360

Rogers DJ, Appan SG (1973) Manihot, Manihotoides (Euphorbiaceae). In: Flora Neotropica (Monograph No. 13). Hafner Press, New York

Rohlf, FJ (1994) NTSYS-pc: Numerical Taxonomy and Multivariate System, version 1.80. Exeter Software, Setauket, New York

SAS Institute Inc (1989) SAS/STAT User's Guide 4th edn Vol 2, SAS Institute, Inc, Cary, North Carolina

Sneath PHA, Sokal RR (1973) Numerical taxonomy. Freeman, San Francisco, California

Tohme J, González DO, Beebe S, Duque MC (1996) AFLP analysis of gene pools of a wild bean core collection. Crop Sci $36: 1375-1384$

Vos P, Hogers R, Bleeker M, Reljans M, van de Lee T, Hornes M, Frijters A, Pot J, Peleman J, Kuiper M, Zabeau M (1995) AFLP: a new technique for DNA fingerprinting. Nucleic Acids Res $21: 4407-4414$ 